\title{
Effect of specimen size on ultimate compressive strength of Bio-coke produced from green tea grounds
}

\author{
Satoru MIZUNO*, Tamio IDA**, Manabu FUCHIHATA** and Kunihiko NAMBA*** \\ ${ }^{*}$ Research Institute of Biocoke \\ 3-4-1 Kowakae Higashiosaka-shi, Osaka 577-8502, Japan \\ E-mail: biocoke@kindai.ac.jp \\ ** Faculty of Science and Engineering, Kinki University \\ 3-4-1 Kowakae Higashiosaka-shi, Osaka 577-8502, Japan \\ *** Osaka Prefecture University College of Technology \\ 26-12 Neyagawa-shi, Osaka 572-8572, Japan
}

Received 11 August 2015

\begin{abstract}
Various sizes of high-density biomass briquette, named 'Bio-coke,' were produced from spent green tea grounds. The mechanical properties at room temperature of the Bio-coke samples were investigated using a compression testing machine. From the results, the relationship between the specimen size of Bio-coke and the ultimate compressive strength at room temperature showed that the ultimate compressive strength depends on the specimen size of Bio-coke. The maximum value of the ultimate compressive strength among the different specimen sizes of Bio-coke was at $67 \mathrm{MPa}$, obtained from the 12-mm diameter sample. In addition, at $12 \mathrm{~mm}$ diameter or smaller, there is hardly any difference in the ultimate compressive strengths measured. Hence, the cold compressive strength properties are divided into two groups based on the uniformity of the structure of the main components along the horizontal cross section of a Bio-coke. Results indicate that the state of the structure, composed of cellulose, hemi-cellulose, and lignin, appears to be consistent resulting from uniform permeation conditions at the 12-mm diameter or smaller samples. Meanwhile, at diameters of $20 \mathrm{~mm}$ or larger, the condition of the periphery of the samples were not consistent with that of the middle region because of the temperature, stress gradient and number of void occurring inside the Bio-coke caused by specimen size effect.
\end{abstract}

Key words : Bio-coke, Room temperature environment, Ultimate compressive strength, Size effect, Thickness of permeation zone

\section{Introduction}

Japan is one of the countries with the largest consumption of fossil fuels, even though it has very little sources of coal, oil, and natural gas. Especially, after the great East Japan earthquake (The Federation of Electric Power Companies of Japan, 2015), the above-mentioned fossil fuels are needed for electric power generation because of the influence of nuclear power plant shutdown. As a result, the amount of primary energy resources imported from supplying nations is going to increase year after year. The development of Japan's domestic primary energy resources is necessary to reduce its dependency on foreign energy import. Since the diminution in this dependency could be a possibility by tapping into sustainable energy resources, much attention is being focused on biomass-derived energy in substituting the conventional primary energy.

The huge quantities of biomass in Japan are distributed thinly over a wide area. Primarily, to advance the utilization of waste biomass, like spent green tea, is one way to be able to effectively utilize domestic biomass resources into alternative energy. Utilization development such as this would greatly help the cascade cyclic utilization of waste biomass. One of the solidification technologies that could utilize biomass is the patented Bio-coke technology (PAT.- 
No.4088933) (Ida, et al., 2005, Ida, et al., 2006). It is shown on the patent that Bio-coke technology is utilizable chemical reactions of three main components (cellulose, hemi-cellulose and lignin) included biomass (Ida and Nakanishi, 2005) by stuffing into a hermetically sealed cylinder and molding with heat and pressure. Hence, the biomass solid fuel, Biocoke, has high volume reduction ratio and high strength characteristic at ordinary temperatures. The high volume reduction ratio is due to Bio-coke having high apparent specific gravity of $1.20 \sim 1.38$ (Ida, et al., 2005, Mizuno, et al. 2012, Torii, et al., 2012), about 3.5 times the apparent specific gravity of wood biomass. Bio-coke's compressive strength is approximately $60 \sim 200 \mathrm{MPa}$ at ordinary temperature (Ida, et al., 2005, Mizuno, et al. 2012, Torii, et al., 2012). However, the effect on the ultimate compressive strength by differences of specimen size has not been described on the patent and not investigated yet.

This study focused its attention on spent green tea grounds that are being disposed at a commercial (large) and domestic (small) scale every day. Because of the difference of plant scale-like blast furnaces and cupola furnaces, various diameters of Bio-coke from spent green tea grounds were produced. Also, the compressive strengths of these Bio-cokes were measured with a compression testing machine under room temperature as a simple evaluation method because Biocokes with high compressive strength at room temperature shows the tendency with higher compressive strength at high temperature (Mizuno, et al., 2015). It is indicated that Bio-cokes with similar form and different sizes seem to have a constant relationship with the ultimate compressive strength at room temperature. The objective of the study is to clarify the effect of the specimen sizes on the mechanical properties of Bio-cokes.

\section{Equipment and procedure}

\subsection{Measurement of thermal analysis}

In order to evaluate the thermochemical characteristic of raw materials before the production of Bio-coke, yield of weight and exothermic and endothermic properties were determined with a thermogravimetry/differential thermal analyzer (TG/DTA).

Table 1 shows the conditions of thermal analysis, while Fig. 1 shows a schematic drawing of TG/DTA device. The TG/DTA analysis was carried out under the gas atmosphere of air to observe behavior of raw spent green tea grounds in the same atmosphere as the production. Also, Fig. 2 describes an example of result obtained from a TG/DTA analysis.

Table 1 Conditions of thermal analysis

\begin{tabular}{cc}
\hline Sample weight $[\mathrm{mg}]$ & 10 \\
\hline Gas flow rate $\left[\mathrm{cm}^{3} / \mathrm{min}\right]$ & 200 \\
\hline Gas atmosphere & Air \\
\hline Maximum temperature $[\mathrm{K}]$ & 1273 \\
\hline Heating rate $[\mathrm{K} / \mathrm{min}]$ & 10 \\
\hline
\end{tabular}

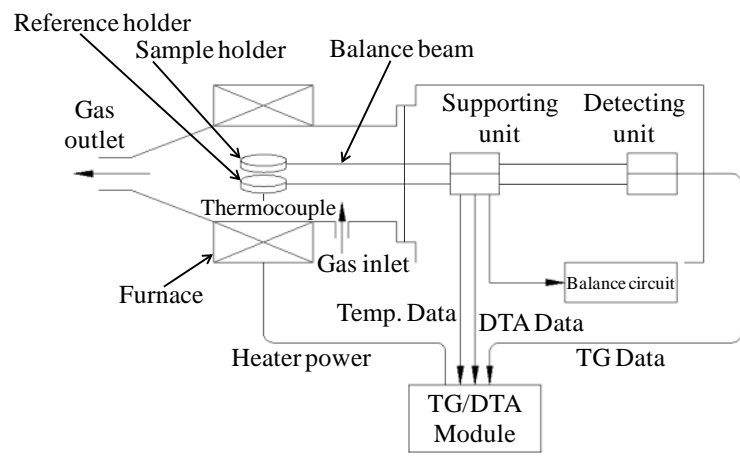

Fig. 1 Schematic drawing of TG/DTA device

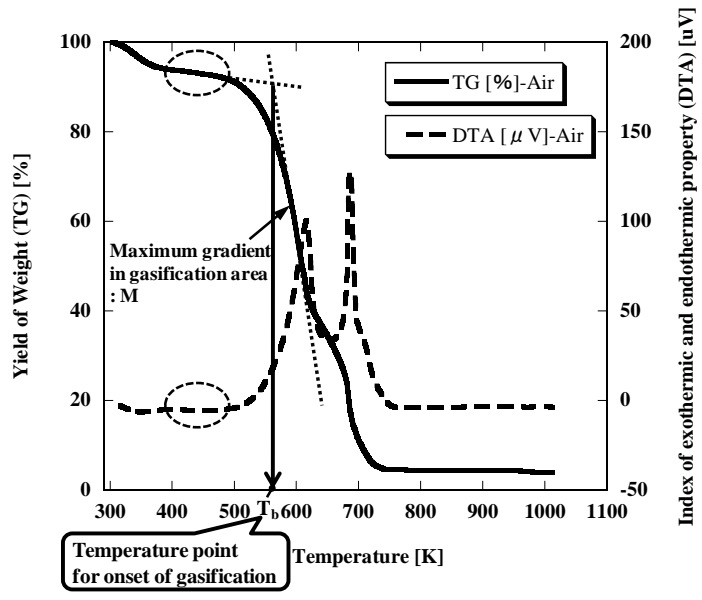

Fig. 2 Example of thermal decomposition curve with condition point and term of gradient for gasification effect of raw biomass. The yield of weight (TG) shows change ratio of initial weight for a rise of heating temperature. The index of exothermic and endothermic property (DTA) shows reactions of exothermic or endothermic by change in state of sample for a rise of heating temperature. 
Table 2 Manufacturing conditions of various sizes of Bio-coke

\begin{tabular}{|c|c|c|c|c|c|c|c|}
\hline Sample & $\begin{array}{l}\text { Size of Bio-coke } \\
\text { (Diameter) } \\
{[\mathrm{mm}]}\end{array}$ & $\begin{array}{c}\text { Aspect Ratio } \\
(\mathrm{h} / \mathrm{d}) \\
{[-]}\end{array}$ & $\begin{array}{c}\text { Initial } \\
\text { Water Content } \\
{[\%]}\end{array}$ & $\begin{array}{c}\text { Production } \\
\text { Temperature } \\
{[\mathrm{K}]}\end{array}$ & $\begin{array}{c}\text { Initial } \\
\text { Weight } \\
{[\mathrm{g}]^{* 1}}\end{array}$ & $\begin{array}{l}\text { Loading Force } \\
\qquad[\mathrm{kN}]\end{array}$ & $\begin{array}{l}\text { Retention Time } \\
{[\text { min] }}\end{array}$ \\
\hline \multirow{6}{*}{ Spent Green Tea } & 8 & \multirow{6}{*}{1.7} & \multirow[t]{6}{*}{ 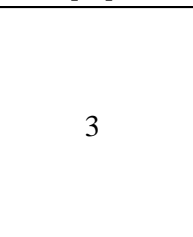 } & \multirow{6}{*}{443} & 0.93 & 1.09 & 2.5 \\
\hline & 12 & & & & 3.13 & 2.45 & 3.75 \\
\hline & 20 & & & & 14.47 & 6.82 & 6.25 \\
\hline & 30 & & & & 48.83 & 15.34 & 9.38 \\
\hline & 40 & & & & 115.74 & 27.27 & 12.5 \\
\hline & 48 & & & & 200 & 39.27 & 15 \\
\hline
\end{tabular}

*1 This value includes moisture.

The left vertical axis in Fig. 2 indicates the TG data, and the right vertical axis indicates the DTA data. Fig. 2 also shows the starting temperature of gasification, $\mathrm{Tb}$, and the maximum gradient in gasification area. The point of $\mathrm{Tb}$ is defined as the intersection point of the extended line in horizontally flat area before the gasification area with the maximum gradient line in the gasification area on the TG curve. The maximum gradient indicates the gasification ratio and ignitability of raw biomass (Mizuno, et al., 2008).

In this study, the change in the thermal decomposition properties for spent green tea grounds up to the gasification region was observed using a TG/DTA analyzer. From the TG/DTA result, the production temperature of Bio-coke from spent green tea grounds was determined at the middle temperature in the flat region as demonstrated the dotted circle lines on the TG curve and the DTA curve in Fig.2.

\subsection{Production and measurement of Bio-coke}

This study is based on an alternative coal coke technology which the authors developed (Ida, et al., 2005, Ida, et al., 2006). In this study, spent green tea grounds, a daily disposed herby biomass, were used to produce Bio-coke. The same manufacturing conditions for each specimen size of Bio-coke such as initial water content and production temperature were adopted. Especially, the production temperature was set as the vicinity of softening start temperature of hemicellulose in the temperature range derived by the TG/DTA analysis (Sano and Honjo, 2011). Also, based on a similarity rule, loading force was determined to add the same loading pressure, $21.7 \mathrm{MPa}$, on the material, and retention time was set linearly with the diameter to see as a simple one-dimensional heat transfer model. Table 2 lists the manufacturing conditions, and Fig. 3 shows a schematic drawing of the molding device. Based on Table 2 and Fig. 3, the production method of Bio-coke starts with measuring the material weight. The measured material is stuffed into a cylinder and sealed with molds. Then, the top of the mold in the sealed cylinder is applied pressure at the foregoing setting conditions. After putting the top mold under the setting pressure, the cylinder is enclosed with an electric heating furnace, and a thermocouple is inserted into the top mold to control the production temperature. The set cylinder, in this condition, is heated until it reaches a specified temperature. Afterward, the production temperature is held during the determined retention time. After waiting until a prescribed time, the furnace is taken off and the cylinder is cooled down to room temperature with an electric fan. With the above production process of Bio-coke, six different specimens of Bio-coke were produced with diameters of $8,12,20,30,40$ and $48 \mathrm{~mm}$. All six specimens have the aspect ratio of 1:1.7 (diameter:height). The aspect ratio is decided on the angle and position of the buckling that results from shearing force. The angle of buckling is about $40 \sim 60$ degrees, which appears in the middle of the longitudinal compression specimens (Sato, 1985, Sugita and Ohono, 2006). Pictures of the specimens are shown in Fig. 4, wherein all specimen sizes are black-colored on all exposed surfaces (top, sides, and bottom).

The compressive stress-strain diagram and ultimate compressive strength for each specimen size of Bio-coke at room temperature were investigated and discussed. The strength at room temperature was measured with a SHIMADZU AG-300kNX compression testing machine. Fig. 5 describes the schematic drawing of the compression testing machine. Bio-coke, without putting lubricant on both the top and bottom sides, was set on the sample table and pressure was applied from the top at a loading rate of $1.5 \mathrm{~mm} / \mathrm{min}$. A computer records the data at $10 \mathrm{~ms}$ intervals during the cold compression test. Through the derived data, the compressive strain is estimated from the movement of the crosshead for the elapsed time and the initial height of Bio-coke. Also, the compressive stress is estimated from the loading force 


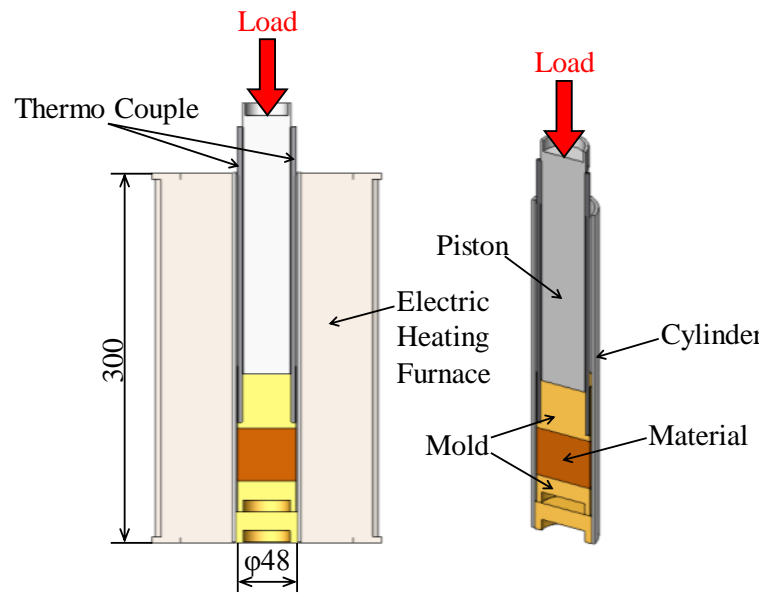

Fig. 3 Schematic drawing of production device for Bio-coke of $\varphi 48 \mathrm{~mm}$

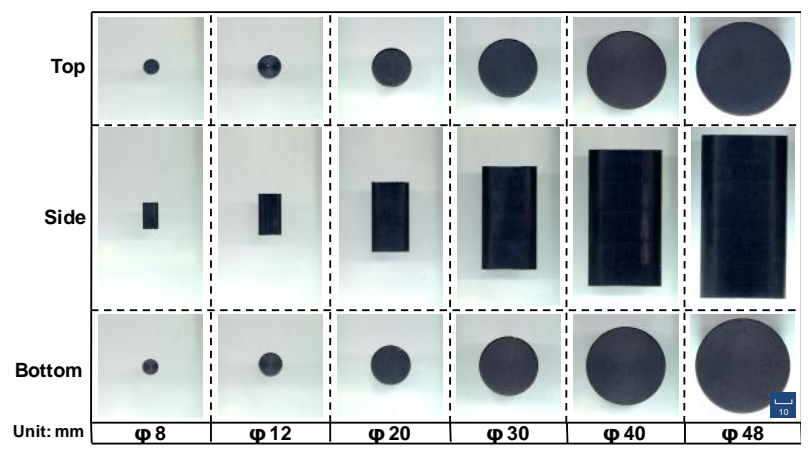

Fig. 4 Appearance of Bio-coke from green tea grounds for each diameter

measured by a load cell.

\section{Results and discussion}

\subsection{Pyrolysis characterization}

Fig. 6 reveals the result of TG/DTA analysis using air-dried spent green tea grounds as raw material. From Fig. 6 , the starting temperature of gasification, $\mathrm{Tb}$, is $520 \mathrm{~K}$, while the maximum gradient of the gasification area, $\mathrm{M}$, is $0.44 \times 10^{-}$ ${ }^{2}[1 / \mathrm{K}]$. It can be noticed that the onset point for the gasification temperature is low and the maximum gradient is gradual in comparison to other biomass. $\mathrm{Tb}$ and $\mathrm{M}$ of trunk of cedar, for instance, are $570 \mathrm{~K}$ and $1.0 \times 10^{-2}$ [1/K] (Mizuno, et al., 2011, Mizuno, et al., 2008). An almost horizontally flat region can also be noticed, which has almost no weight loss on the TG curve and does not demonstrate either endothermic or exothermic peaks on the DTA curve. The temperature range of the flat region is from $370 \mathrm{~K}$ to $520 \mathrm{~K}$. This temperature range coincides with the evaporating temperature of water and the softening temperature of hemi-cellulose associated with hydrolysis until the starting temperature of gasification (Sano and Honjo, 2011). From this investigation of the thermal decomposition properties and the previous research about the same herby biomass as spent green tea grounds (Mizuno, et al. 2012), the optimum temperature to mold Bio-coke with the highest apparent specific gravity and the highest compressive strength is determined from the middle of the flat region.

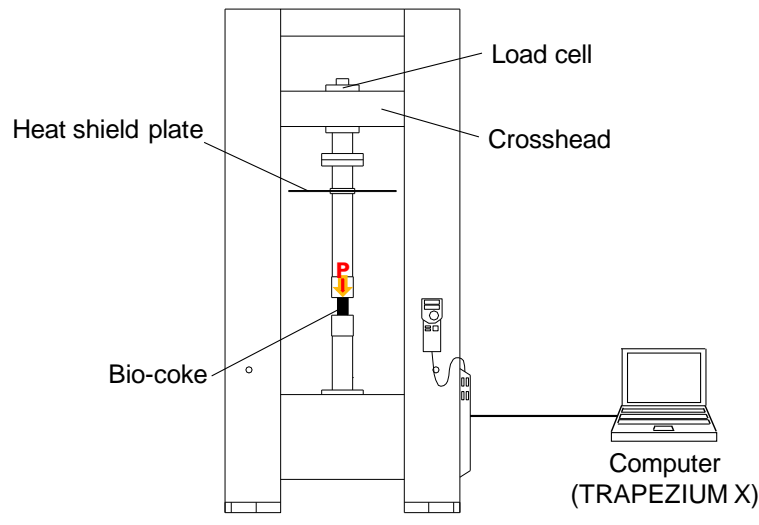

Fig. 5 Schematic drawing of the compression testing machine

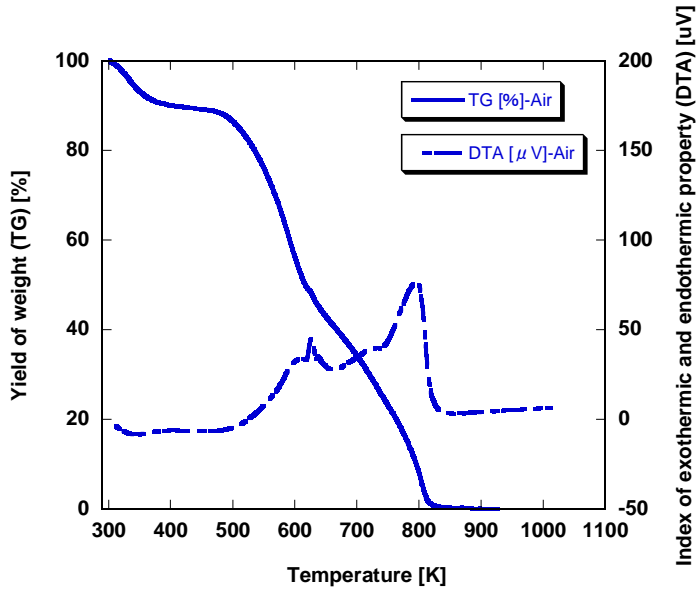

Fig. 6 Thermal decomposition curve for green tea grounds 


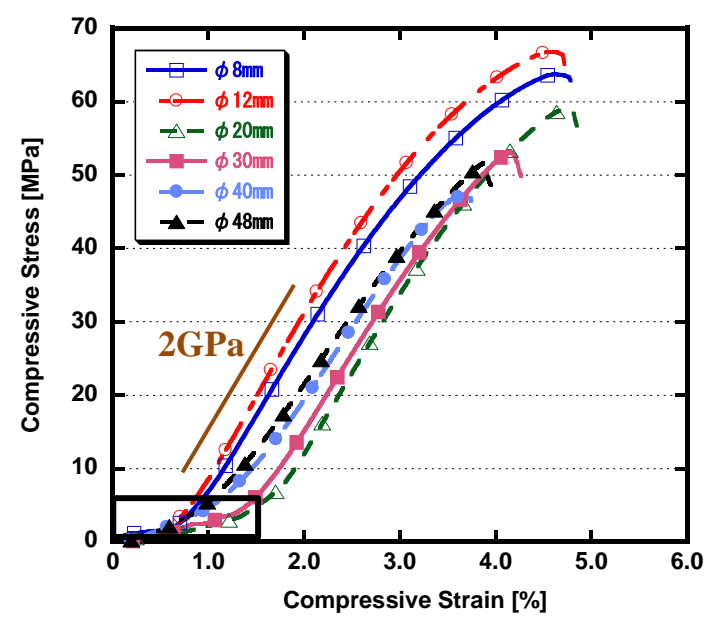

Fig. 7 Compressive stress-strain diagram of each Bio-coke at room temperature

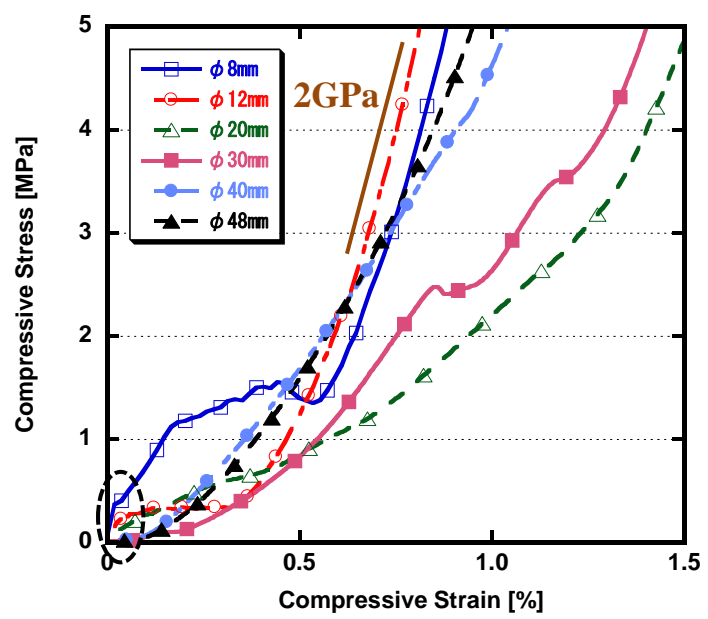

Fig. 8 Enlarged view of compressive stress-strain diagram of each Bio-coke at room temperature of the rectangular enclosure in Fig. 7.

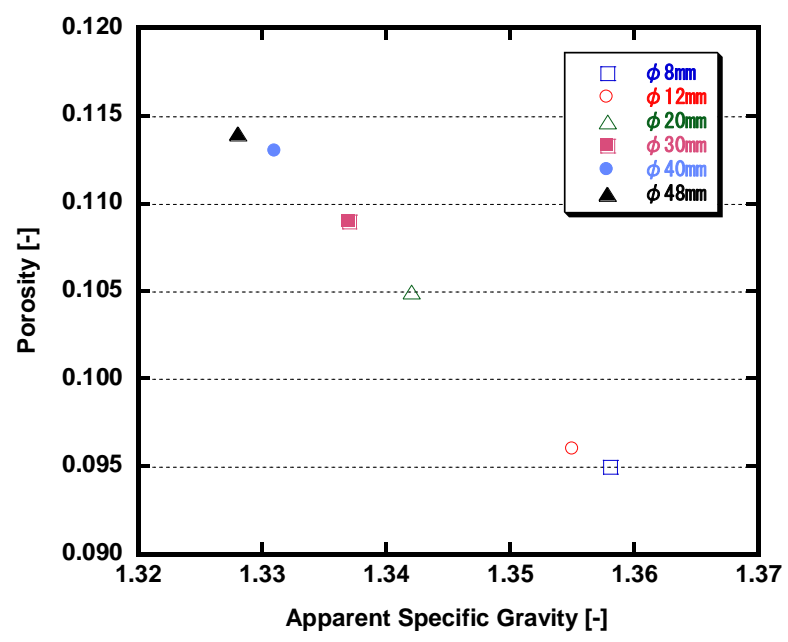

Fig. 9 Relationship between apparent specific gravity and porosity for each Bio-coke

\subsection{Mechanical characteristic: compressive strength}

Fig. 7 shows a compressive stress-strain diagram derived from the cold compression test for each specimen size of Bio-coke. Fig. 7 shows that the compressive stress is slightly increasing for all specimens up to a strain of $0.5 \%$. Fig. 8 magnifies the region of the compressive strain from 0 to $1.5 \%$ and the compressive stress of 0 to $5 \mathrm{MPa}$. Fig. 8 demonstrates that initial gradients are small and different for each specimen size of Bio-coke. As Bio-coke has innumerable fine voids within, these voids seem to have been compressed by vertical pressure at the initial phase of the compression test. Fig. 9 shows the relationship between apparent specific gravity and porosity for each specimen sizes. It is indicated that the diameters of Bio-cokes increase with decreasing the apparent specific gravity and increasing the porosity. Hence, the initial strength and gradient of Bio-coke are too low and small. Also from Figure 8, it is considered that the insides of small diameter samples seem to be homogeneous because the initial strains enclosed by dotted circle in the $\phi 8 \mathrm{~mm}$ and $\phi 12 \mathrm{~mm}$ Bio-cokes are much steeper gradient than those seen in the other bigger diameter sample. These results suggests that $\phi 8 \mathrm{~mm}$ and $\phi 12 \mathrm{~mm}$ samples have minimal voids within although the Bio-cokes were molded as satisfying the similarity rule. It is conjectured that hemi-cellulose included in $\phi 8 \mathrm{~mm}$ and $\phi 12 \mathrm{~mm}$ samples is easily softened on the whole and fills in the voids as the small samples are homogeneously heated up until their center of cylindrical cross section of Bio-coke.

Focusing on compressive strain in Fig. 7, it can be noticed that the ultimate compressive strengths of all the specimens 
are within about $4.0 \sim 4.5 \%$ of their compressive strain and not dependent on the diameter sizes. Quasi-Young's modulus are defined as the maximum gradient while straining from $0 \%$ to $4.5 \%$ of specimens' initial height. Quasi-Young's moduli also demonstrate almost similar gradients for all the specimens, wherein the value of Quasi-Young's moduli is approximately $2 \mathrm{GPa}$ (shown in Fig. 7). It is inferred that the existence of the permeation area by softened hemi-cellulose of the cross section direction of Bio-coke is the key factor; therefore, the obtained compressive strain and Quasi-Young's moduli are affected by the adhesive strength among particles of spent green tea grounds by hemi-cellulose.

Fig. 10 illustrates a cross section image of the solidification permeation states inside a Bio-coke. In the manufacturing process of Bio-coke, the properties of the three main components of the biomass: cellulose, hemi-cellulose, and lignin, were considered. Above all, it is considered that the adhesive force of hemi-cellulose affects compressive strength. Due to the material being heated up from the outside, solid-state by adhesion of hemi-cellulose proceed through thermal conduction from the outer periphery in a radial direction towards the center of cylindrical cross section (Mizuno, et al. 2010). Although the homogeneous permeation of hemi-cellulose included the biomass proceed along the cross sections with heat transfer up to a certain scale, the permeation do not efficiently reach the center of Bio-coke as sample diameter increases with increasing an inhomogeneous permeation area. A doughnut-shaped region in the cross sections indicates differences in permeation conditions of softened hemi-cellulose penetrating with heat during the formation of Bio-coke. Inhomogeneous permeation area occurs at the center shown as gray region in Fig. 10, wherein the spent green tea ground material are close to still being raw. The hardness of the inhomogeneous permeation area is therefore lower than that of the homogeneous permeation area. Thus, it is speculated that the Quasi-Young's moduli in doughnut-shaped region of different specimen sizes of Bio-coke are the same value because the characteristics of the homogeneous permeation area are composed of the adhesive force of hemi-cellulose.

Figure 11 shows the relationship between each sample diameter and cold ultimate compressive strength. The plots for each specimen size of Bio-coke in Fig. 11 are average values for the compression test done in triplicates. The ultimate compressive strengths of $\phi 8 \mathrm{~mm}, \phi 12 \mathrm{~mm}$ and $\phi 20 \mathrm{~mm}$ Bio-cokes are almost similar values at approximately 60 MPa. These results indicate that a homogeneous permeation occurred along the plane of the cross section in these samples during formation, and the doughnut-shaped phenomenon hardly occurs until the diameter increases up to more than 20 $\mathrm{mm}$. In contrast, the ultimate compressive strength of samples more than $20 \mathrm{~mm}$ in diameter decreases linearly with increase in sample diameter. From this result, the doughnut-shaped region also decreases as the center of the cross section is not penetrated enough with heat from the periphery with increase in sample diameter. It is considered that this reduction phenomenon of the doughnut-shaped region results in decrease in the compressive strength because of the fact that the hardness of Bio-coke comes from the adhesive force of hemi-cellulose in the doughnut-shaped region. In conclusion, it is clarified that the compressive strength is affected by the size of Bio-coke if the Bio-coke of different size is molded with the production conditions based on the similarity rule suggested in this study.

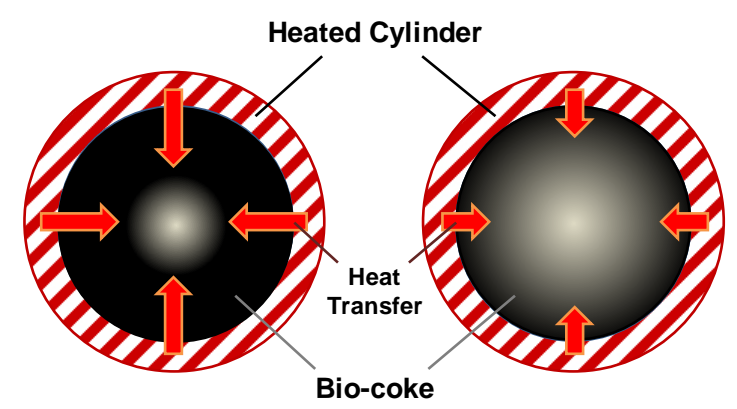

(a) $\phi 8 \mathrm{~mm} \sim \phi 20 \mathrm{~mm}$

(b) $\phi 30 \mathrm{~mm} \sim \phi 48 \mathrm{~mm}$

Fig. 10 Image of permeation area inside of Bio-coke viewed from cross section direction

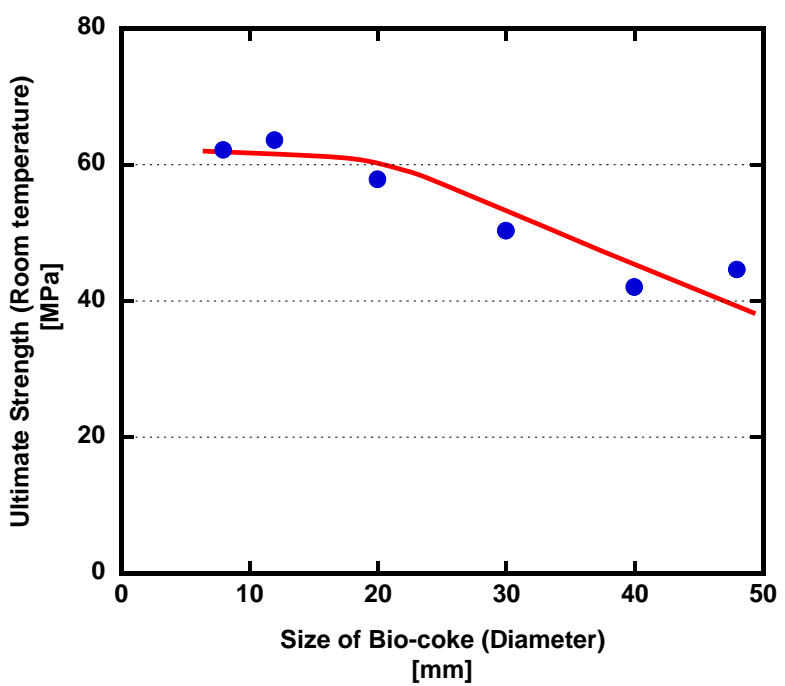

Fig. 11 Ultimate compressive strength of each Bio-coke specimen size at room temperature 


\section{Conclusions}

The following conclusions were derived from the results and discussion:

1. The optimum producing temperature of Bio-coke exists in the middle of the temperature range of the almost horizontally flat region between $370 \mathrm{~K}$ and $520 \mathrm{~K}$ that shows neither weight loss nor endothermic or exothermic peaks.

2. The Quasi-Young's moduli are of the same value for the different diameter sizes of Bio-coke. However, the ultimate compressive strength has a boundary at sample diameter of about $20 \mathrm{~mm}$, wherein at $20 \mathrm{~mm}$ diameter or less, the ultimate compressive strength has similar values; and as the sample diameter increases to more than $20 \mathrm{~mm}$, the ultimate compressive strength decreases.

3. The Quasi-Young's modulus of the homogeneous layer is approximately $2 \mathrm{GPa}$, and its ultimate compressive strength is approximately $60 \mathrm{MPa}$.

4. The compressive strength is affected by the size of Bio-coke if the Bio-coke of different size is molded with the production conditions based on the similarity rule suggested in this study.

\section{Acknowledgement}

A part of this work was supported by, "Biomass energy technology research and development / The strategic next generation biomass energy utilization technology development business (the next generation technology development) / Research and development high-density and high-carbonized solid fuel based on advanced torrefaction technology," from New Energy and Industrial Technology Development Organization (NEDO) in 2011. We are grateful to them.

\section{References}

Ida, T., Fuchihata, M., Sawai, T. and Sano, H., Alternative Coal Coke by Woody Biomass (in Japanese), The Japan Society of Mechanical Engineering, Vol.80, No.054-1 (2005), pp.13-14.

Ida, T. and Nakanishi, A., A Property as Solid Fuel of Woody Biomass and Its limitation (in Japanese), The Japan Institute of Marine Engineering, Vol.40, No.6 (2005), pp.35-38.

Ida, T., Nakanishi, A. and Osaka TLO, Patent Number 4088933 (in Japanese) (2006).

Mizuno, S., Ida, T. and Fuchihata, M., A Study of Physical Properties of High-Density Solid Biomass, Bio-coke, with Unutilized Biomass, Journal of the Japanese Society for Experimental Mechanics, Vol.11 (2011), pp.s19-s24.

Mizuno, S., Ida, T., Fuchihata, M., Sanchez Jr, E. and Yoshikuni, K., Formation Characteristics of Bio-coke Produced from Waste Agricultural Biomass, Proceedings of InterPACK/ICNMM2015, (2015).

Mizuno, S., Ida, T., Fuchihata, M., Namba, K., Kakosaka, A. and Fujita, O., Formation Characteristics of High-density and High-hardness New Briquette Based on Herby Biomass (in Japanese), Journal of the Japan Institute of Energy, Vol.91, No.1 (2012), pp.41-47.

Mizuno, S., Ida, T. and Namba, K., Characteristics of Internal Thermal Conduction into High-Density Solid Biomass, Closing Asymptotically to Apparent Specific Gravity 1.4 (in Japanese), Journal of High Temperature Society, Vol.36, No.1 (2010), pp.31-35.

Mizuno, S., Morita, A., Ida, T., Namba, K., Fuchihata, M. and Sawai, T., A Property Extracted by Composition / Thermal Decomposition Analyses of Various Biomass Resources and Its Correlation (in Japanese), Journal of High Temperature Society, Vol.34, No.4 (2008), pp.153-159.

Sano, H. and Honjo, T., Principle of Semi-carbonization of Biomass and the Effect on Use (in Japanese), Journal of High Temperature Society, Vol.37, No.2 (2011), pp.43-49.

Sato, K., Influence of Strain Rate on Tensile and Compressive Strengths of Beech (in Japanese), Journal of the Society of Materials Science, Vol.34, No.383 (1985), pp.915-917.

Sugita, K. and Ohono, S., Influence the Size of the Piece of Examination Affects Vertical Compressive Strength (in Japanese), Transactions of Architectural Institute of Japan, (2006), pp.1007-1008.

The Federation of Electric Power Companies of Japan, Electric Power Statistical Information (in Japanese) (online), available from <http://www.fepc.or.jp/library/data/tokei/index.html>, (accessed on 6 August, 2015).

Torii, Y., Mizuno, S., Nishi, K., Ichino, Y., Ohmasa, M., Sawai, T., Ida, T. and Fuchihata, M., Forming Characteristics of Bio-coke with a Mixture of Bamboo and Carbonized Japanese Cedar (in Japanese), Journal of Smart Processing 
Mizuno, Ida, Fuchihata and Namba, Mechanical Engineering Journal, Vol.3, No.1 (2016)

Society for Materials, Environment \& Energy, Vol.1, No.2 (2012), pp63-70. 